\title{
Um caminho para viver melhor
}

\author{
José Mauricio de Carvalho ${ }^{l}$ \\ Universidade Federal de São João del-Rei
}

TRICHES, I. J. Um caminho para viver melhor. Curitiba: Editecne, 2010.

$\mathrm{N}$ a obra o autor desenvolve o conceito de práxis-orgânica que ele emprega na definição da vida plena. Atribui-lhe dez dimensões que explora nos capítulos do livro. O pano de fundo do texto é o diálogo com a filosofia clínica, que teve, segundo sua confissão, um impacto profundo em seu pensamento. O livro tem prefácio de Lúcio Packter, criador da Filosofia Clínica, que destaca tanto a trajetória do autor quanto o caráter humanista e didático do texto. A aproximação com a filosofia clínica se mostra logo nas primeiras palavras do livro, quando o autor revela sua intenção de "contribuir para que as ações cotidianas se tornem cada vez melhores" (p. 14). O livro possui portanto um propósito moral, notadamente pelo diálogo que faz com Aristóteles na busca da vida plena e feliz. Ivo Triches adota o projeto do mestre grego de orientar a conduta humana para a felicidade, reconhecendo o papel da racionalidade e das virtudes na realização de uma vida humana plena. De fato, para Aristóteles, o objetivo da existência do homem é a felicidade, ideal identificado e deduzido da condição do homem. O livro tem uma característica peculiar que o autor destaca: a grande quantidade de notas de rodapé, espaço que destina ao exame do significado das palavras e a origem etimológica delas.

No primeiro capítulo, o autor apresenta o conceito que preside a obra: práxis-orgânica. Esclarece que práxis no sentido que utiliza representa a "união dialética entre a teoria e a prática" (p. 17) e orgânica é uma referência geral a condição de ser vivo. Nota que os seres vivos estão em relação com o seu entorno, de modo a assegurar a continuidade do processo vital. Na sequência do texto esclarece que identifica dez dimensões numa vida plena, embora seja possível experimentar um ir vivendo sem desenvolver algumas das dimensões que aponta. Fica subentendido que o que ele trata por vida com dez dimensões é a humana e não a vida dos vegetais ou dos animais, pois apenas ela pode possuir as características que enumera.

A primeira das dimensões é a teórica, significando tal dimensão a busca ampla da verdade que se pretende conhecer. Teoria refere-se à capacidade de formular certo tipo de conhecimento. $\mathrm{O}$ conhecimento se refere tanto às verdades filosóficas como as científicas. Ambas possuem finalidade prática, a de nos ajudar a viver melhor e a prolongar a vida que temos. Em certo sentido,

${ }^{1}$ Endereço para correspondências: Departamento de Filosofia, Universidade Federal de São João delRei, Praça Frei Orlando, 170, Centro, São João del-Rei, MG, 36307-352 (mauricio@ufsj.edu.br). 


\section{HUMANAS}

o caráter pragmático com que trata do conhecimento humano recorda o propósito orteguiano de aproximar ao ato de pensar da vida mesma, jamais separando o pensar do viver. Um conhecimento teórico afastado de sua realidade vital é beataria, diria o filósofo espanhol José Ortega y Gasset.

O outro capítulo é dedicado à ação. Nele explica que o homem não apenas pensa o mundo, mas age sobre ele. O conhecimento teórico é importante, mas não se conhece apenas por conhecer, mas para aplicar o material conhecido. Ivo Triches lembra que aprendeu da prática clínica que há pessoas "que vivem quase que o tempo todo no mundo das abstrações" (p. 35), mas considera que o desafio é estabelecer "um equilíbrio entre ambas as atitudes" (p. 36). Neste capítulo já se delineia o ritmo do diálogo com a Filosofia Clínica, o autor observa que a clínica revela que há pessoas que vivem apenas algumas das dimensões mencionadas. A Filosofia Clínica mesma não indica que se tenha que viver todas estas dimensões, é o autor percebendo que nem todos os homens as experimentam propõe o conjunto delas como um ideal de vida.

A dimensão seguinte é a tékne. Ele lembra que desenvolver a técnica é uma forma de permitir que a dimensão prática da vida seja usada numa melhor relação com o mundo. Quando se diz que "alguém tem uma determinada técnica, é porque consegue fazer algo com muita habilidade" (p. 39). O uso da técnica é uma característica marcante da sociedade atual, fruto de três grandes revoluções pelas quais passou a sociedade nos últimos três séculos: a da máquina, no dezoito; a energia elétrica, no seguinte; e a cibernética, no passado. O desenvolvimento rápido da tecnologia é resultado da aproximação entre a ciência moderna e a técnica, e esta característica tornou a cultura ocidental muito forte. Por conta de seu uso freqüente e generalizado, dificilmente, alguém vive, hoje, afastado da tecnologia.

Em seguida, o autor trata do comprometimento. Ele pretende afastar suas considerações dos modelos éticos mais comuns, pois trata do compromisso como sendo um acordo consigo mesmo, um esforço para melhorar o próprio endereço existencial. O que propõe é algo semelhante ao projeto vital de Ortega y Gasset, que obriga a uma fidelidade ao núcleo mais íntimo de nossa singularidade pessoal. Este compromisso não se faz sem uma análise intelectual. Ele diz que "quando uma pessoa se compromete, de fato, com alguma coisa é porque antes ela pensou, refletiu e depois, então, agirá" (p. 54). Este compromisso conosco obriga a fazer bem nosso papel social porque quando respeitamos nossa vocação nos comprometemos.

Sociabilidade é outra dimensão examinada pelo autor. Ele a define, acompanhando a compreensão sociológica, como "a arte de bem viver em sociedade" (p. 59). Embora todos vivam em sociedade, nem todos o fazem adequadamente. Ele explica: "nas organizações, muitas vezes, existem pessoas que conseguiram assimilar as quatro primeiras dimensões, mas não esta quinta" (p. 61). 
Ivo Triches associa a capacidade de bem viver à inteligência emocional, entendida como a capacidade de tomar decisões racionais nos momentos de emoção intensa. Para a vivência adequada desta dimensão é necessário desenvolver de comunicação, pois, só através dela será possível "resolver nossos problemas" (p. 64).

A dimensão do escolher-se completa a do comprometimento, como já se assinalou anteriormente. Escolher-se "significa irmos ao encontro de nós mesmos; buscarmos aquilo que mais nos realiza como pessoa" (p. 67). Quem está afastado deste comprometimento sofre mais a angústia do domingo à noite, quando o aborrecimento de uma vida longe do núcleo íntimo da personalidade aborrece e atormenta. Muitas pessoas realizam uma recíproca de inversão, isto é, vivem projetos alheios. Como esclarece o autor: "esquecem de viver seus projetos para viver nos e com os projetos dos seus filhos" (p. 70). Este escolher-se, o autor colheu das lições da fenomenologia existencial, onde a existência do homem é fruto de suas opções. A atitude pode vir a qualquer tempo porque esta fidelidade a si mesmo é uma possibilidade permanente.

A sétima dimensão da práxis-orgânica é a poiésis. Ivo denomina poiésis a capacidade humana de criar soluções novas para desafios que surgem na vida. Ele diz que poiésis "consiste em uma ação particular do homem que é o ato de fabricar algo" (p. 74). A clínica filosófica mostra que muitas vezes dificultamos o outro de escolher o que fabricar, o que fazer. Assim procedemos porque podemos errar em nossas próprias escolhas. É importante deixar ao outro o caminho de suas soluções.

A dimensão que se segue é o humanismo. $\mathrm{O}$ autor esclarece que esta dimensão foi retirada dos ensinamentos de Spinoza. Spinoza foi perseguido e expulso da sinagoga, mas conservou a serenidade e o equilíbrio no trato com as pessoas. O humanismo exige "o cuidado para que as pessoas com quem mantemos contatos sociais não sejam por nós humilhadas, rejeitadas" (p. 86). Em síntese, o humanismo representa para o autor o que consideramos seja o principal valor da cultura ocidental: a pessoa humana. Reconhecê-la como tal é uma atitude humanista.

A penúltima dimensão é o alterdidatismo. Trata-se de uma abertura ao outro que faz parte da minha vida. "Alterdidata é o que estuda com o outro. Não é aquele que procura guardar o que sabe apenas na sua memória ou na memória do seu computador. É aquele que tenta guardar o que sabe no coração dos seus amigos" (p. 92). Esta dimensão acena para a humildade, pois quando estudo com o outro reconheço que ele pode me ensinar algo e que sempre aprendo quando me aproximo de alguém.

A última dimensão é a vontade. Este conceito o autor busca na obra de Arthur Schopenhauer. O filósofo coloca na vontade a raiz última da luta pela sobrevivência. "Por isso ela é omnilateral, no sentido de que é parte integrante do todo, de todos os elementos constituintes da natureza" (p. 100). 


\section{HUMANAS}

A vontade traduz o impulso para realizar algo que conheço ou escolhi. A vontade forte significa, para o autor, uma espécie de virtude que ele aproxima da noção de escolha presente na moral aristotélica. No livro III da Ética a Nicômaco, Aristóteles divide as escolhas em voluntárias e involuntárias, sendo apenas as primeiras louvadas ou censuradas. A realização da virtude exige esforço e isto explica a importância da vontade em nossa vida. Diz o autor: "estou convencido de que, para chegarmos a ela (virtude), o hábito da vontade é imprescindível" (p.108).

O livro termina com um elogio à amizade, considerada o coroamento da vida humana. A amizade é uma das formas de amor, diz o autor. Há outras, como o amor erótico, o amor pelos pais, pela ciência, etc. Valendo-se das lições de Aristóteles, o autor considera a amizade fundamental para a vida, em especial num mundo cibernético que favorece o isolamento e os contatos atrás das máquinas. Apresenta os conceitos de amizade útil, subordinada ao interesse; a agradável, sustentada pelo prazer; concluindo que só a amizade perfeita é realmente significativa. Define-a, repetindo Aristóteles, como "aquela que existe entre os homens que são bons e semelhantes na virtude, pois tais pessoas desejam o bem um ao outro de modo idêntico e são bons em si mesmos" (p. 119). Assim, o amigo de verdade é aquele que ajuda o outro a encontrar o caminho do bem.

O livro de Ivo Triches descreve as dimensões do que ele considera seja uma vida plena. A sua preocupação fundamental é didática, de modo que as referências à tradição filosófica são curtas e de fácil compreensão. Os capítulos são curtos e de leitura agradável. A Filosofia Clínica funciona como pano de fundo das considerações que ele faz ao viver. $\mathrm{O}$ autor se vale das indicações da técnica sobre singularidade existencial para explicar que nem todos vivem todas as dimensões enumeradas por ele e, mesmo quando as vivem, não o fazem do mesmo modo. 